\title{
Realism of rainfall in a very high-resolution regional climate model
}

Article

Published Version

Kendon, E. J., Roberts, N. M., Senior, C. A. and Roberts, M. J. (2012) Realism of rainfall in a very high-resolution regional climate model. Journal of Climate, 25 (17). pp. 5791-5806. ISSN 1520-0442 doi: https://doi.org/10.1175/JCLI-D-1100562.1 Available at https://centaur.reading.ac.uk/31222/

It is advisable to refer to the publisher's version if you intend to cite from the work. See Guidance on citing.

Published version at: http://dx.doi.org/10.1175/JCLI-D-11-00562.1

To link to this article DOI: http://dx.doi.org/10.1175/JCLI-D-11-00562.1

Publisher: American Meteorological Society

Publisher statement: () Copyright 2012 of the American Meteorological Society. The AMS Copyright Policy is available on the AMS web site at http://www.ametsoc.org

All outputs in CentAUR are protected by Intellectual Property Rights law, including copyright law. Copyright and IPR is retained by the creators or other copyright holders. Terms and conditions for use of this material are defined in the End User Agreement.

www.reading.ac.uk/centaur

\section{CentAUR}


Central Archive at the University of Reading

Reading's research outputs online 


\title{
Realism of Rainfall in a Very High-Resolution Regional Climate Model
}

\author{
ELIZABETH J. KENDON \\ Met Office Hadley Centre, Exeter, United Kingdom \\ Nigel M. RoBERTS \\ Joint Centre for Mesoscale Meteorology, Met Office, Reading, United Kingdom \\ Catherine A. Senior And Malcolm J. Roberts \\ Met Office Hadley Centre, Exeter, United Kingdom
}

(Manuscript received 26 September 2011, in final form 21 February 2012)

\begin{abstract}
The realistic representation of rainfall on the local scale in climate models remains a key challenge. Realism encompasses the full spatial and temporal structure of rainfall, and is a key indicator of model skill in representing the underlying processes. In particular, if rainfall is more realistic in a climate model, there is greater confidence in its projections of future change.

In this study, the realism of rainfall in a very high-resolution $(1.5 \mathrm{~km})$ regional climate model $(\mathrm{RCM})$ is compared to a coarser-resolution 12-km RCM. This is the first time a convection-permitting model has been run for an extended period (1989-2008) over a region of the United Kingdom, allowing the characteristics of rainfall to be evaluated in a climatological sense. In particular, the duration and spatial extent of hourly rainfall across the southern United Kingdom is examined, with a key focus on heavy rainfall.

Rainfall in the $1.5-\mathrm{km} \mathrm{RCM}$ is found to be much more realistic than in the 12-km RCM. In the 12-km RCM, heavy rain events are not heavy enough, and tend to be too persistent and widespread. While the $1.5-\mathrm{km}$ model does have a tendency for heavy rain to be too intense, it still gives a much better representation of its duration and spatial extent. Long-standing problems in climate models, such as the tendency for too much persistent light rain and errors in the diurnal cycle, are also considerably reduced in the $1.5-\mathrm{km} \mathrm{RCM}$. Biases in the 12-km RCM appear to be linked to deficiencies in the representation of convection.
\end{abstract}

\section{Introduction}

Climate models are our primary tool for understanding how the climate may change in the future with increasing greenhouse gases. They indicate that changes in rainfall are likely in many regions of the world (Solomon et al. 2007). Of particular concern are changes in extreme rainfall due to its considerable impact on society and natural ecosystems. However, our confidence in model projections of changes in local precipitation extremes is limited because of deficiencies in the representation of small-scale processes (Maraun et al. 2010).

Corresponding author address: Elizabeth Kendon (née Kennett), Met Office Hadley Centre, Fitzroy Road, Exeter EX1 3PB, United Kingdom.

E-mail: elizabeth.kendon@metoffice.gov.uk
The realistic representation of rainfall on the local scale in climate models is a key challenge.

Regional climate models (RCMs), which have a higher resolution than global climate models (GCMs) but span a limited area, are widely used to provide projections of how the climate may change locally (Christensen et al. 2007). They typically have a horizontal resolution ofabout $10-50 \mathrm{~km}$, giving a better representation of mountains and coastlines and also finescale $O(10$ $100 \mathrm{~km}$ ) physical and dynamical processes (Christensen and Christensen 2007). In general, RCMs are able to capture the average statistics of daily precipitation on scales of a few grid boxes. They show greatest agreement with observations for moderate precipitation intensities, with model biases increasing for heavier events (Boberg et al. 2009; Kjellström et al. 2010). RCMs also tend to underestimate the number of dry days (Fowler et al. 
2007), with a tendency for too much persistent light rain (Boberg et al. 2009). This is a common problem across climate models and is also seen in GCMs (Dai 2006). On subdaily time scales, there are greater deficiencies. In particular, the diurnal cycle of convection is not well represented in RCMs (Brockhaus et al. 2008) and neither are hourly precipitation extremes (Lenderink and van Meijgaard 2008).

A known source of error in the simulation of precipitation in current global and regional climate models is the convective parameterization scheme (Hohenegger et al. 2008). These schemes aim to describe the average properties of convection over a model grid box and pass that information as increments of temperature, moisture, and momentum at the grid scale. It is vital to parameterize the effects of unresolved convection on the atmospheric column, which would otherwise become increasingly unrealistic and unstable. Convection schemes have largely been developed for coarse resolution $(>50 \mathrm{~km})$ models and for tropical convection (Hohenegger et al. 2008) for which the underlying assumptions are most valid. Thus, such schemes are less appropriate outside the tropics and for higher resolution RCMs with grid spacings of $\sim 10-20 \mathrm{~km}$ (Swann 2001). Even in the coarser-resolution models in which the convection schemes were designed to operate, they are only meant to represent average effects. Thus, even if the convection scheme worked perfectly for higher resolution RCMs, it would not and is not designed to represent individual storms and locally high rainfall events. Deficiencies and inherent limitations of the convection scheme are likely to be major contributors to RCM errors in the representation of daily precipitation extremes in summer over Europe (Frei et al. 2006; May 2007) and the United Kingdom (Fowler and Ekström 2009) and precipitation intensities on subdaily time scales related to convective showers (Lenderink and van Meijgaard 2008).

There is evidence that RCM skill in simulating the spatial and temporal characteristics of rainfall increases with increasing model resolution (Boberg et al. 2010; Rauscher et al. 2010). This is due to the improved representation of complex topography and land surface processes. Additionally, as kilometer-scale horizontal resolutions are achieved it becomes possible to explicitly represent convection on the model grid without the need for a convective parameterization scheme. At these resolutions models are termed "convection permitting," as larger convective storms and mesoscale organization are permitted but convective plumes and smaller showers are still not resolved. Such convection-permitting models give an improved representation of the diurnal cycle of convection (Hohenegger et al. 2008) and hourly precipitation extremes (Wakazuki et al. 2008). The use of convection-permitting models is now common practice in numerical weather prediction (NWP) (Roberts and Lean 2008), but is computationally very expensive on longer time scales. Thus there are very few examples of such resolutions being applied in climate studies, and these are limited to small domains and often just the summer season (Hohenegger et al. 2008; Wakazuki et al. 2008; Knote et al. 2010).

The Met Office is currently routinely running a NWP forecast model with $1.5-\mathrm{km}$ horizontal resolution over the United Kingdom (the UKV model). Experiments have shown that kilometer-scale NWP models provide a significantly improved representation of both topographically enhanced and convective precipitation (Roberts et al. 2009; Roberts and Lean 2008; Lean et al. 2008), compared to coarser resolution models. Kilometerscale models are able to generate realistic showers with a better representation of the initiation and organization of convection and can forecast localized extreme events, which are not captured at coarser resolutions. Such events can be the result of storm stationarity or the repeated generation of convective cells in the same area. Accurate forecasts rely on a good representation of the local environment and storm dynamics. The benefit of using a storm-permitting resolution has also been seen in other models and for other parts of the world (Schwartz et al. 2009; Weusthoff et al. 2010).

In this study, for the first time, we have used a $1.5-\mathrm{km}$ version of the Met Office model to carry out a $20-\mathrm{yr}$ length climate simulation over a region of the United Kingdom. Our aim is to get a better understanding of rainfall processes and deficiencies in coarser-resolution climate models. Of particular interest is heavy rainfall, and the extent to which current climate models capture the key processes important for predicting its future change. Significantly, Hohenegger et al. (2009) find that the sign of soil moisture-precipitation feedback reverses in a convection-permitting model, which suggests the importance of carrying out extended length climate simulations at these scales to capture long-term memory in the soils and investigate feedbacks with precipitation. Current climate models indicate that changes in soil moisture and feedbacks with precipitation are a key driver of future changes in rainfall over Europe (Kendon et al. 2010). The extent to which the representation of local storm dynamics is important for future predictions is currently unknown.

A first step, adopted here, is to examine the realism of rainfall in the $1.5-\mathrm{km}$ model in terms of its spatial and temporal structure and compare this to a $12-\mathrm{km}$ RCM. For the first time we are able to evaluate this in a climatological sense rather than relying on individual case 
studies since the multiyear simulation allows us to build up average statistics of hourly rainfall in the $1.5-\mathrm{km}$ model. Realism is used here as a key indicator of model skill in representing the underlying processes. A complete assessment would encompass the full spatial and temporal characteristics of rainfall across a range of space and time scales, and as a function of the meteorological situation. As such, it has only been possible to examine some aspects here, specifically focusing on the duration and spatial extent of heavy rainfall on the hourly time scale.

\section{Methodology}

\section{a. Model data}

A version of the 1.5-km UKV forecast model, but with a smaller domain (Fig. 1), has been run here as a climate model (1.5-km RCM). Apart from using a different domain, this climate version is identical to the UKV in formulation. The UKV is one of the several configurations of the Met Office Unified Model (UM) (Cullen 1993), which is used for both weather and climate applications. It solves nonhydrostatic, deep atmosphere dynamics using a semi-implicit, semi-Lagrangian numerical scheme (Davies et al. 2005) and includes a comprehensive set of parameterizations describing the land surface (Essery et al. 2001), boundary layer (Lock et al. 2000), convection (Gregory and Rowntree 1990), and cloud microphysics (Wilson and Ballard 1999), which have all since been improved. The UKV also includes a Smagorinsky-Lilly subgrid turbulence diffusion scheme [based on Smagorinsky (1963) and Lilly (1962), and described in Brown et al. (1994)] to represent turbulent mixing in strongly sheared areas such as the edges of convective updrafts. This is the first time a $1.5-\mathrm{km}$ version of the UM has been run in climate mode for an extended period of time. The $1.5-\mathrm{km}$ RCM is free running in the interior with the model atmosphere and land surface evolving freely in response to information fed in at the lateral and sea surface boundaries.

A grid spacing of $1.5 \mathrm{~km}$ was chosen because it is the highest storm-permitting resolution used in the UM for short-range forecasting and has therefore already been tested and run routinely. For weather-forecasting purposes, it is the finest affordable resolution at which most convection over the United Kingdom is satisfactorily represented on the grid without the need for a convection scheme (Lean et al. 2008; Roberts 2007). The convection scheme has therefore been switched off, with rainfall only coming from the resolved model dynamics. This is a key advantage, as many of the deficiencies in climate models have been linked to the convective

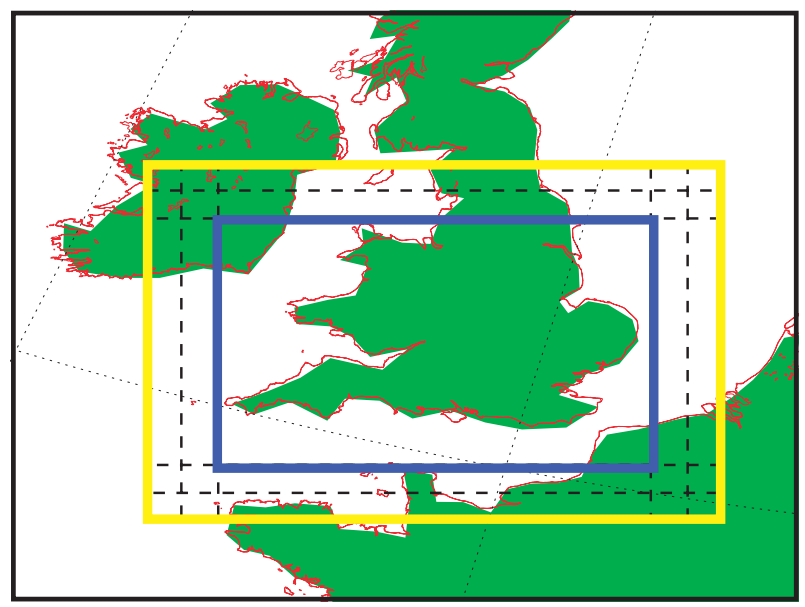

FIG. 1. Domain of the $1.5 \mathrm{-km}$ climate model. Shown is the boundary of the $1.5-\mathrm{km}$ resolution inner region (blue box) and the variable resolution rim (yellow box). The variable resolution rim consists of 11 grid boxes with 4-km grid spacing (yellow to black dashed line) and 21 grid boxes with decreasing grid spacing from 4 to $1.5 \mathrm{~km}$ (black dashed line to blue).

parameterization scheme (section 1). It should be noted that even at $1.5 \mathrm{~km}$ convection is not completely resolved; in particular, the grid spacing is still too coarse to properly resolve updrafts that are narrower than several kilometers. Nevertheless, extensive testing within NWP trials indicates that the model produces realistic-looking showers with the convection scheme switched off. This is illustrated in Fig. 2, where the forecast from the $1.5-\mathrm{km}$ model for a recent flooding event in the United Kingdom can be seen to be much more realistic than that from the $12-\mathrm{km}$ model that relies on a convective parameterization scheme. In this case the UKV model was able to produce organized large convective showers, which persisted and moved eastward into the evening. The 12-km model by comparison could not organize convection and was unable to produce the observed high rainfall accumulations. This improvement in the $1.5-\mathrm{km}$ model is typical for localized convective storms.

The domain for the $1.5-\mathrm{km}$ RCM spans southern England and Wales (Fig. 1). This was the largest domain possible to allow completion of decadal-length simulations in a reasonable time. The chosen domain includes regions with very different rainfall characteristics. In particular, it includes southern England, where there is a high proportion of convective events in summer; London, where the urban environment has a considerable influence on the local climate; the mountainous region of Wales, where there is orographic enhancement of rainfall; and the English Channel, to allow mesoscale convective systems traveling from France to spin up before reaching the United Kingdom. Thus this domain should 

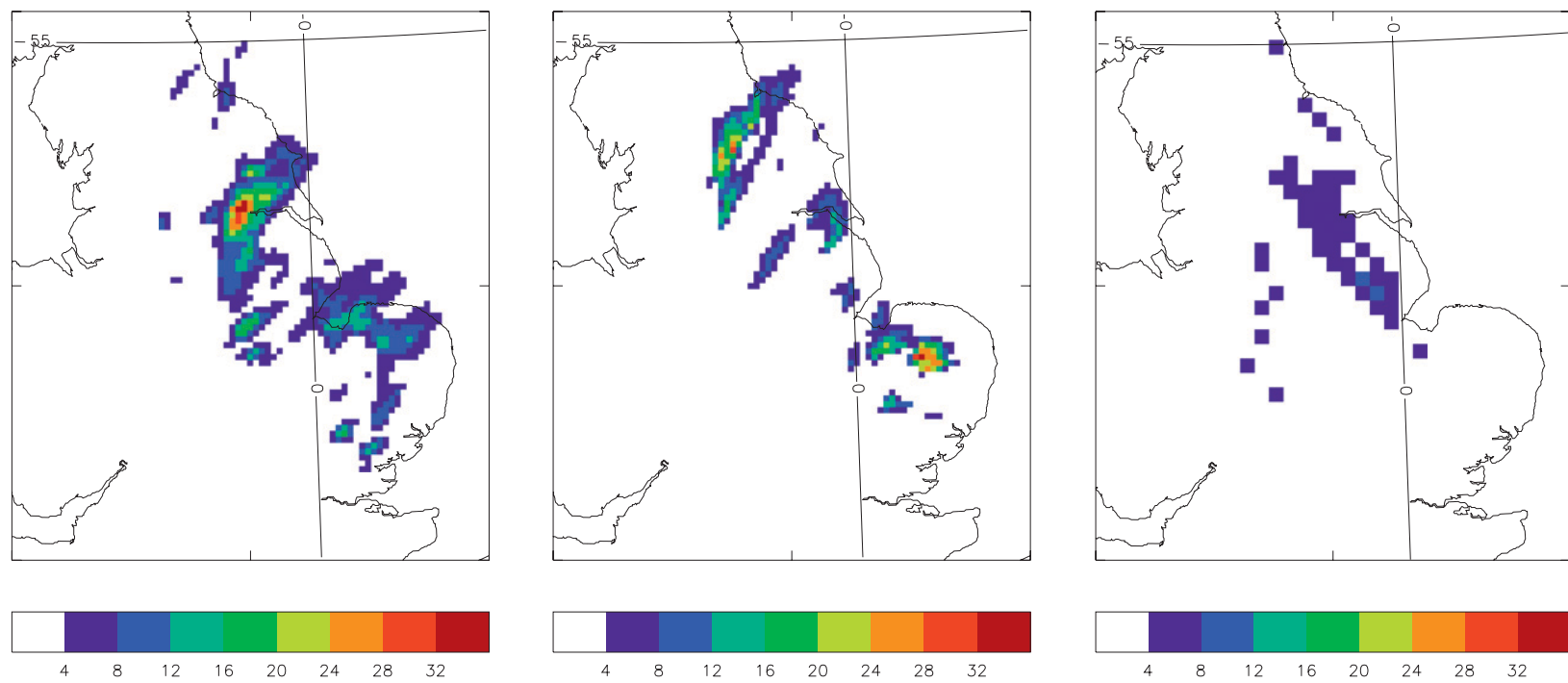

FIG. 2. Rainfall accumulations (mm) for the 4-h period 1500-1900 LT 3 Aug 2011 for the (left) radar, (middle) 1.5-km UKV model, and (right) 12-km North Atlantic European (NAE) model. Rainfall amounts from the UKV have been aggregated onto the 5-km radar grid.

allow many of the anticipated benefits of high resolutionnamely, improved representation of mountains, the coastline, and small-scale convective and land surface processes-to be examined.

The $1.5-\mathrm{km}$ RCM has been run for a 20 -yr period (1989-2008) driven by a 12-km regional climate model (12-km RCM). The 1.5-km RCM has a variable resolution horizontal grid; it has a grid spacing of $1.5 \mathrm{~km}$ within the interior (blue rectangle in Fig. 1) including a transition to grid spacings of $1.5 \mathrm{~km} \times 4 \mathrm{~km}$ near the edge or $4 \mathrm{~km} \times 4 \mathrm{~km}$ near the corners (yellow rectangle in Fig. 1). This variable grid creates less of a difference in grid spacing between the high-resolution model and the $12-\mathrm{km}$ driving model, and thus acts to reduce numerical errors and instabilities near the boundaries. The slightly coarser (but still storm permitting) resolution toward the edge also allows a larger domain and therefore more time for small-scale rainfall features to spin up within flows entering the domain.

The 12-km RCM used here is a limited-area atmosphereonly version of the latest Met Office Hadley Centre Global Environmental Model (HadGEM3-RA). This is also a configuration of the Met Office Unified Model (version GA3.0) and the model physics are described in Walters et al. (2011). The model physics in the $12-\mathrm{km}$ RCM are very similar to those in the $1.5-\mathrm{km} \mathrm{RCM}$, although there are a few notable differences, which are summarized in Table 1. In particular, the $12-\mathrm{km} \mathrm{RCM}$ uses a convection scheme based on Gregory and Rowntree (1990). It is run without any horizontal diffusion, while the SmagorinskyLilly turbulence diffusion is applied in the $1.5-\mathrm{km}$ model. The $12-\mathrm{km}$ model assumes that rain falls directly to the ground without being advected by the winds. This approximation is increasingly poor at higher resolution, so prognostic rain is used in the $1.5-\mathrm{km} \mathrm{RCM}$. The 12-km RCM, however, does include prognostic cloud (PC), which is currently not included in the 1.5$\mathrm{km}$ RCM because of insufficient testing at this resolution and less justification for clouds to be treated statistically.

The 12-km RCM spans Europe, with its western boundary extending to the mid-Atlantic. It is driven at its lateral boundaries by the latest European Centre for Medium-Range Weather Forecasts Re-Analysis (ERAInterim) for the period from 1989 to present (Dee et al. 2011). The 12-km RCM in turn supplies lateral boundary conditions to the $1.5-\mathrm{km}$ RCM with an hourly update

TABLE 1. Notable differences in model physics between the $1.5-\mathrm{km}$ and $12-\mathrm{km}$ configurations of the Met Office Unified Model used in this study.

\begin{tabular}{|c|c|c|}
\hline Model property & 1.5-km RCM & 12-km RCM \\
\hline $\begin{array}{l}\text { Horizontal } \\
\text { resolution }\end{array}$ & $\begin{array}{l}1.5 \mathrm{~km} \text {, with variable } \\
\text { resolution rim }\end{array}$ & $12 \mathrm{~km}$ \\
\hline $\begin{array}{l}\text { Vertical } \\
\text { resolution }\end{array}$ & 70 levels & 63 levels \\
\hline Time step & $50 \mathrm{~s}$ & $5 \mathrm{~min}$ \\
\hline $\begin{array}{l}\text { Convection } \\
\text { scheme }\end{array}$ & None & $\begin{array}{l}\text { Gregory and } \\
\text { Rowntree } \\
\text { (1990) scheme }\end{array}$ \\
\hline Prognostic rain & Yes & No \\
\hline $\begin{array}{l}\text { Prognostic cloud } \\
\text { scheme }\end{array}$ & No & PC2 scheme \\
\hline $\begin{array}{l}\text { Horizontal } \\
\text { diffusion }\end{array}$ & $\begin{array}{l}\text { Smagorinsky-Lilly } \\
\text { turbulence scheme }\end{array}$ & None \\
\hline
\end{tabular}


frequency. At the surface, sea surface temperatures (SSTs) are supplied from the high-resolution $\left(0.25^{\circ}\right)$ Reynolds dataset and these are updated daily (Reynolds et al. 2007). Soil moisture in the $1.5-\mathrm{km}$ RCM is initialized from the 12-km RCM, but it then evolves freely using the Met Office Surface Exchange Scheme, version 2 (MOSES2) (Essery et al. 2001). Soil properties are defined using the high-resolution Harmonized World Soil Database (HWSD). The equilibrium soil moisture state in the $1.5-\mathrm{km} \mathrm{RCM}$ is drier than that in the $12-\mathrm{km} \mathrm{RCM}$, consistent with rainfall being less uniform (in time and space) at high resolution and thus less effective at wetting the soils. Preliminary results showed that it takes a few months for soil moisture to spin up in the $1.5-\mathrm{km}$ RCM (except potentially in the very deepest layer, where it can take several years for the soil to fully reach equilibrium), so data from the first nine months of the simulation (corresponding to April-December 1989) were discarded from further analysis.

\section{b. Radar data}

Gridded hourly radar data for the United Kingdom at $5-\mathrm{km}$ resolution are available from the Nimrod database (Golding 1998) for the period 2003-10. These have been used here to assess the spatial and temporal characteristics of hourly rainfall in the $1.5-$ and $12-\mathrm{km}$ RCMs. Although there is considerable overlap between the radar and the model data period, model data are not available for all 8 years of the radar periiod. Specifically the model data span 1989-2008 and, owing to highresolution SST data only currently being available until the end of 2008, it has not been possible to extend the run further. We note, however, that, due to the large size of the 12-km-RCM domain and that observational constraints are only fed in at the lateral and sea surface boundaries, we would not expect the day-to-day series of weather patterns over the United Kingdom in the models to exactly correspond to those in reality even for the same set of years. In this study we are assessing the climatology of hourly rainfall accumulated over several years, which is not expected to vary greatly from one decade to the next. To confirm this, we compare rainfall characteristics in the radar with those in the models for two separate 8-yr model periods (1990-97 and 2000-07). We also only show differences that are significant compared to year-to-year variability (see section $2 \mathrm{c}$ ).

There are many issues with radar data. It can be affected by clutter (e.g., phone masts in the way of the beam), deflection of the beam onto the ground (anomalous propagation), increased signal at the melting level (bright band), assumptions in the conversion of reflectivity to rain/snow rate, evaporation below the beam, and attenuation that may lead to systematic underestimation of heavy rain. It is also less reliable in mountainous areas because the lower-elevation beams may be blocked and unusable and more assumptions then have to be made. All of these effects can lead to errors or biases in the measurement of precipitation amounts. The Met Office calibrates against rain gauges and employs algorithms to take account of the above when producing a U.K. radar composite (Harrison et al. 2000), but the quality control is difficult and some problems cannot be fully rectified. Nevertheless, radar is still particularly useful for capturing the spatial distribution and temporal evolution of precipitation, which is of interest in this study. We would also expect the rank of precipitation at a given point in space or time relative to the full data series to be reliably captured, even if there may be a bias in the absolute rainfall amount. As described below, this is exploited here through the use of percentile thresholds.

Note that throughout this paper we use the term rainfall when strictly we are referring to precipitation. Specifically we are comparing model precipitation (including rain and snow) with hourly precipitation accumulations derived from radar reflectivity. In fact, the majority of precipitation over the United Kingdom (particularly the southern regions considered in this study) is in the form of rain and not snow, but we do not explicitly distinguish these and include both fractions in the analysis.

\section{c. Statistical analysis}

To assess the realism of rainfall in the 1.5 - and $12-\mathrm{km}$ RCMs, we examine the duration and spatial size of rainfall events. The analysis includes all grid points over southern United Kingdom, corresponding to all land points within the 1.5-km-RCM inner domain (blue rectangle in Fig. 1). We use 8 years of hourly precipitation data from each of the datasets, corresponding to the years 1990-97 or 2000-07 for the models and 2003-10 for the radar. The analysis is performed at the $12-\mathrm{km}$ RCM scale, with the hourly precipitation fields for the $1.5-\mathrm{km}$ model and $5-\mathrm{km}$ radar being first aggregated to the $12-\mathrm{km}$ RCM grid.

For each 12-km grid square across the southern United Kingdom, we identify occurrences of precipitation above a given threshold in the hourly time series. Independent occurrences, or "events," are defined as continuous periods of precipitation exceeding the threshold at a given location. For each event, the duration of precipitation above the threshold is counted and the peak intensity recorded. Each event is then allocated to a duration and peak-intensity bin, and statistics are built up of the total number of events in each bin across all southern U.K. grid boxes and all years in the respective datasets. Similarly, we also examine the spatial size of precipitation cells for each hour in the time series. In this case, cell size 
is given by the number of connected $12-\mathrm{km}$ grid boxes (diagonals are excluded) for which rain exceeds the given threshold. Each cell is binned according to its size, and statistics are built up of the total number of cells in each bin across southern United Kingdom for all years.

A key focus of this study is heavy rainfall and thus we carry out the above analysis for a range of thresholds in the upper tail of the precipitation distribution. Given that radar measurements have an uncertainty and there may well be an underestimation of heavy precipitation amounts, we use percentile (or frequency) thresholds. In particular, for a percentile threshold of $p$, we find the $p$ th percentile of the distribution of hourly rainfall for all southern U.K. grid boxes and all eight years in each of the respective datasets. We then examine the spatiotemporal characteristics of rainfall exceeding this percentile, the absolute value of which will differ between the different datasets. The advantage of this approach is that it removes the effects of bias in precipitation amounts between the models and radar, while still retaining reliable information about precipitation patterns and behavior.

In addition to the use of percentile thresholds to compare the characteristics of heavy rain, we also repeat the analysis for an absolute threshold of $0.1 \mathrm{~mm} \mathrm{~h}^{-1}$. In this case, we aim to include all precipitation events in the analysis, only excluding the very lightest. This approach was used to investigate the extent to which heavy rain is embedded within lower intensity events. It should be noted, however, when comparing absolute precipitation amounts, that biases in the radar data may contribute to model - radar differences.

A bootstrap resampling method was used to assess the significance of $1.5-12-\mathrm{km}$-model or model - radar differences compared to year-to-year variability. For each dataset, 1000 bootstrap samples were produced by selecting 8 years from the 8 -yr dataset randomly with replacement. Thus in a given bootstrap sample, some years may be represented more than once and others not at all. The methodology described above was then applied to each bootstrap sample to calculate the duration and cell size characteristics for that sample. This resulted in 1000 estimates of the probability distribution of rainfall duration or cell size for each dataset, and these were used to produce 1000 estimates of the difference in the probability distributions between the models or between each model and the radar. If the $0.5 \%-99.5 \%$ confidence interval for the difference does not include zero then the difference is significant at the $1 \%$ level. Where a difference is found to be significant compared to year-to-year variability, we also expect it to be significant compared to multidecadal variability. We test this here by showing results for two different 8 -yr model

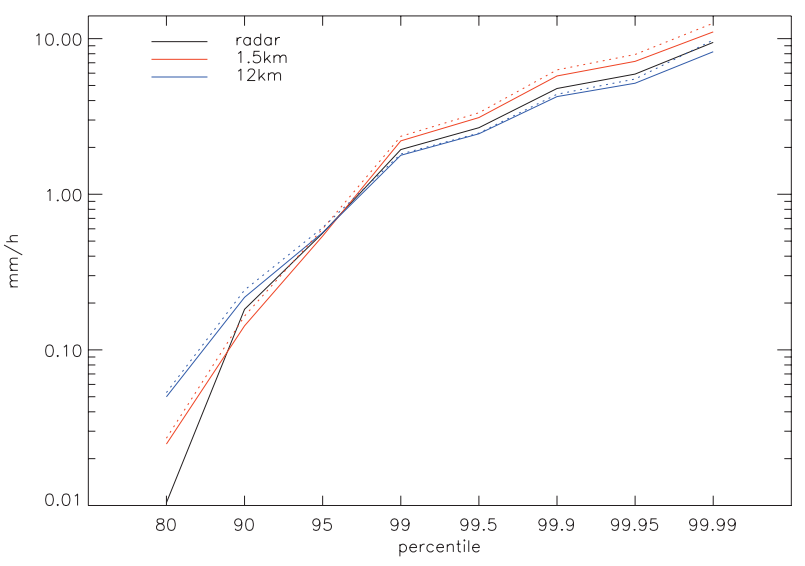

FIG. 3. Hourly rainfall $\left(\mathrm{mm} \mathrm{h}^{-1}\right)$ corresponding to a given percentile threshold in the radar and the $1.5-\mathrm{km}$ and $12-\mathrm{km}$ RCMs. Results correspond to years 2003-10 in the radar and 1990-97 (solid lines) and 2000-07 (dotted lines) in the models. A percentile threshold of $p$ corresponds to the $p$ th percentile of the distribution of hourly rainfall across all grid boxes over the southern United Kingdom and all eight years in the respective datasets.

data periods (1990-97 and 2000-07), confirming that the differences are, indeed, robust to the choice of the 8-yr periods used for the models and the radar.

\section{Results}

\section{a. Hourly precipitation distribution}

Hourly rainfall amounts corresponding to a range of percentile thresholds in the radar, 1.5-, and 12-km RCMs are shown in Fig. 3. The 80th percentile of the hourly precipitation distribution corresponds to light rain of less than $0.1 \mathrm{~mm} \mathrm{~h}^{-1}$ in both the radar and the models. This is a consequence of the large number of hours with no rain such that very high percentile thresholds $(>99)$ are needed to capture heavy rain.

The rainfall rate of the 80 th percentile is lower in the $1.5-\mathrm{km}$ RCM than the $12-\mathrm{km}$ RCM. This reflects the result that the $1.5-\mathrm{km}$ RCM has considerably more dry spells than the $12-\mathrm{km} \mathrm{RCM}$, in much better agreement with observations. It can be seen that this result is robust to the choice of the model data period, with very similar results for model years 1990-97 and 2000-07. The tendency for too much persistent light rain is a common problem in climate models (section 1). We find that this problem is considerably reduced in the $1.5-\mathrm{km} \mathrm{RCM}$ over land, which gives good agreement in the occurrence of dry spells compared to hourly radar data and also (although not shown here) dry days compared to rain gauge observations.

For higher percentile thresholds $(\geq 99)$, the corresponding rainfall amounts are greater in the $1.5-\mathrm{km}$ 
RCM than the 12-km RCM. This reflects the fact that heavy rain is more intense in the $1.5-\mathrm{km} \mathrm{RCM}$. Coarserresolution climate models are known to underestimate the intensity of heavy rain, so an increase in heavy rain amount represents an improvement. However, there is some suggestion that there may be somewhat too much heavy rain in the 1.5-km RCM (apparent for both model data periods assessed here). Although some of the discrepancy is likely to be due to underestimation by radar, the tendency for too much heavy rain in the $1.5-\mathrm{km}$ $\mathrm{RCM}$ is also seen on the daily time scale compared to rain gauge data (not shown). This tendency of highresolution models to show too much heavy rain has also been seen in the context of short-range weather forecasting (Lean et al. 2008) and may be explained by convection still being underresolved (see section 4).

\section{b. Duration of heavy rain}

To investigate whether the characteristics of heavy rain are more realistic in the $1.5-\mathrm{km} \mathrm{RCM}$, we examine the temporal structure and, in particular, focus on one aspect, namely, the duration of heavy rain. Figure 4 shows the probability distribution of rain spell duration for rain exceeding various percentile thresholds. Each horizontal row in the figure corresponds to the probability distribution for rain exceeding a given threshold (defined in Fig. 3), with each box within the row indicating the probability of rain of that category having a given duration. Where model differences are shown, it is instead the difference in these probabilities that is plotted. The use of percentile thresholds removes any bias in the model or radar data that may be present in absolute rainfall amount and is expected to result in the selection of a comparable set of rainfall events (with agreement in the types of rainfall events sampled across the different datasets).

In this Eulerian framework (namely, where the duration of events is examined from the frame of an observer on the ground rather than in the frame of the moving cell), heavier rainfall events tend to be shortlived. In particular, in the radar there are few (less than $5 \%$ ) rainfall events lasting three hours or more for percentile thresholds $\geq 99$.9. Partly this is to do with using percentile thresholds, which by definition limit the number of pixels more for the heavier events. A similar behavior is seen in both models, but there are significant differences in the probability distributions of rainfall duration for a given percentile threshold. In Fig. 4, differences are only plotted where they are significant compared to year-to-year variability at the $1 \%$ level (assessed using the methodology described in section 2c), and also model-radar differences are shown for two different model data periods to assess the robustness of the results to the choice of decade.

In the 12-km RCM, rainfall is too persistent compared to the radar. This is most pronounced for heavy rain (corresponding to percentile thresholds $\geq 99$ ), for which there are not enough events in the $12-\mathrm{km} \mathrm{RCM}$ lasting one hour and too many lasting two hours or more. Heavy rain in the $1.5-\mathrm{km}$ RCM is shorter-lived than in the $12-\mathrm{km}$ RCM, with a significantly greater probability of rain lasting just one hour for all percentile thresholds $\geq 90$. This better agreement with radar represents a considerable improvement. There is still, however, a tendency for rainfall in the $1.5-\mathrm{km}$ RCM to be slightly too persistent compared to the radar.

It should be noted that the use of percentile (or frequency) thresholds means that, if more rain falls in longer-lived events, there will be fewer events (with rain exceeding the threshold) overall. This will act to reduce the discrepancy in the probability of short-lived events since, even though there are fewer short-lived events in this case, they may represent a similar proportion of the total. Thus a significant deficit in the probability of shortlived events (found above for both models compared to the radar) will only occur where there is a significant deficit in the actual number of short-lived events. By contrast, a deficit in the probability of long-lived events may occur due to a deficit in the number of long-lived events or an excess of very short duration events (resulting in an increase in the number of events overall). This latter effect may contribute to some of the $1.5-12-\mathrm{km}$ RCM differences.

The above results are very similar for model years 1990-97 and 2000-07, suggesting that they are robust to the choice of model data period. We also find that there is consistency in the above results across different U.K. regions and seasons. In particular, we examined the duration of heavy rain for Wales, southwest England, central England, and southeast England separately (not shown). In all regions and for all seasons, rain is too persistent in the $12-\mathrm{km} \mathrm{RCM}$, with this bias being considerably reduced in the $1.5-\mathrm{km}$ RCM.

\section{c. Size of heavy rain cells}

To assess the realism of heavy rain in terms of its spatial structure, we examine the size of rainfall cells for rain exceeding a range of percentile thresholds (Fig. 5). Heavier rainfall events tend to be more localized, with a decreasing probability of large rain cells with increasing threshold. Compared to the radar, heavy rainfall in the $12-\mathrm{km} \mathrm{RCM}$ is too widespread. In particular, for heavy rain (percentile thresholds $\geq 99$ ), there are not enough rain cells in the $12-\mathrm{km} \mathrm{RCM}$ consisting of a single grid box and too many consisting of five or more 


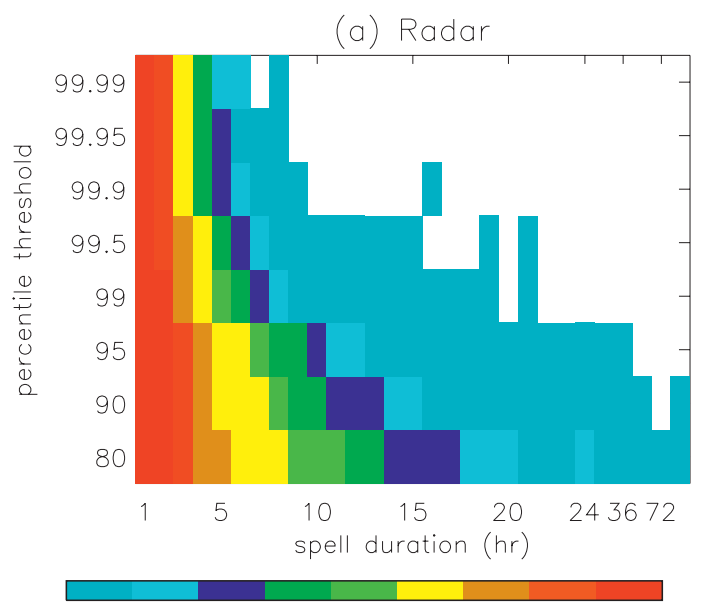

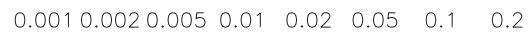
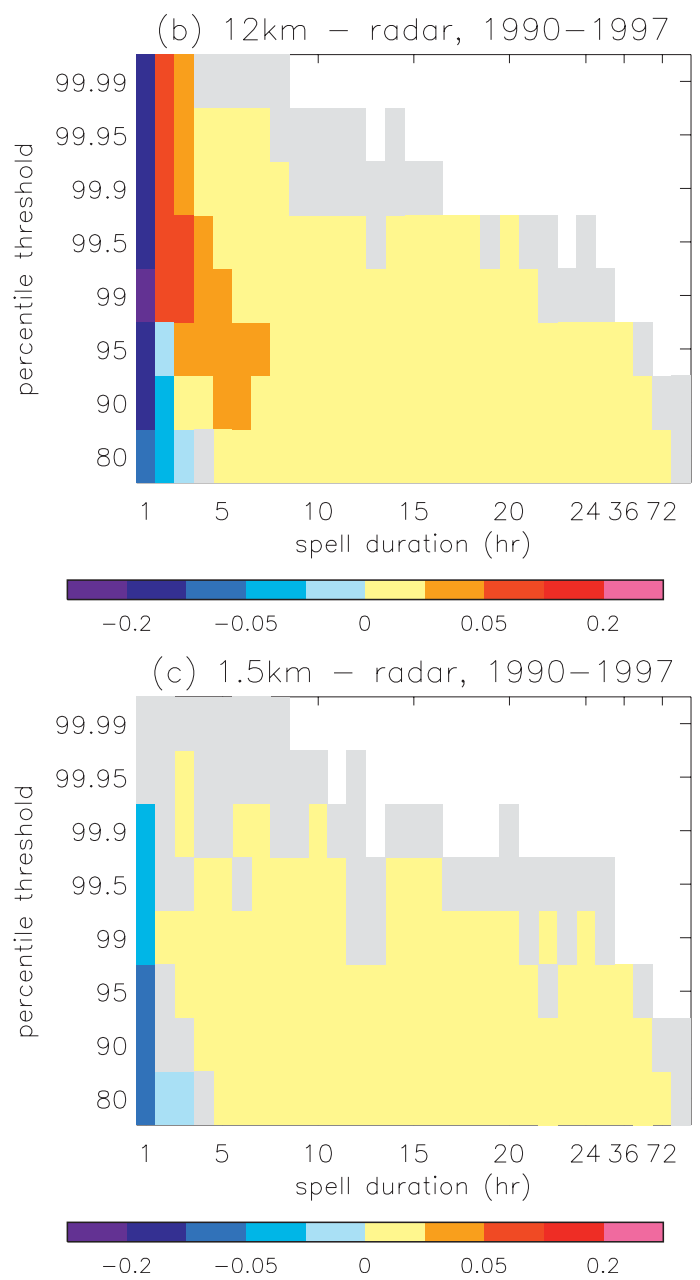
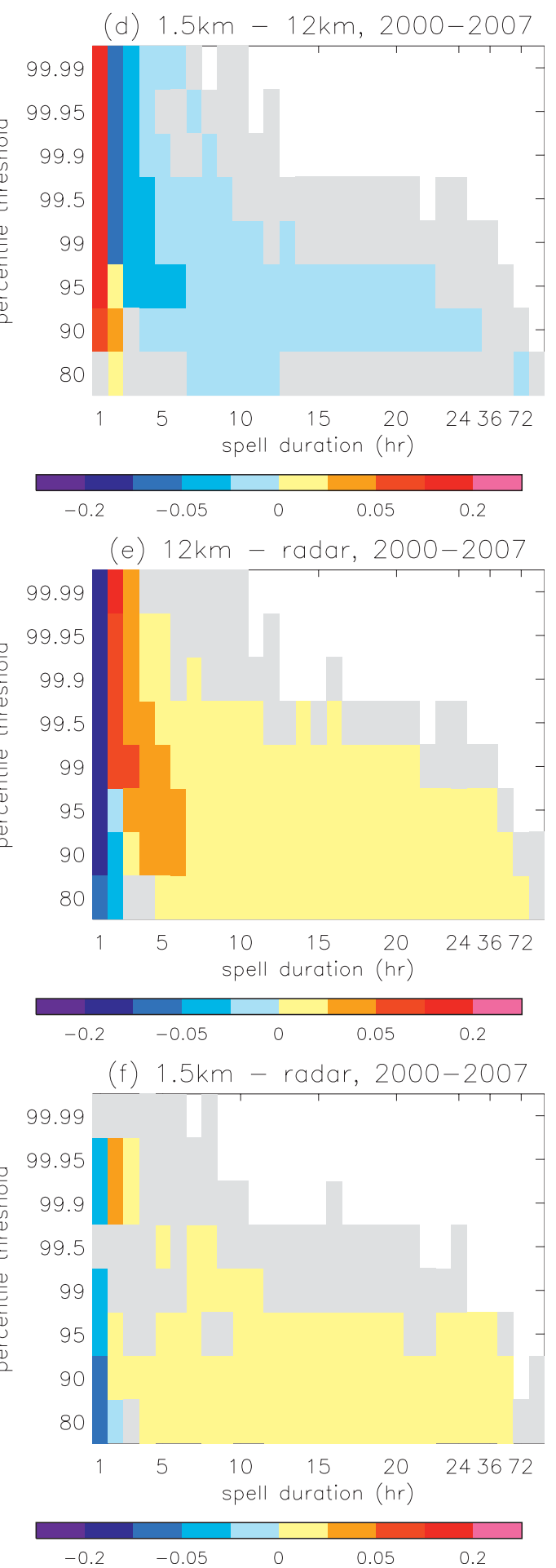

FIG. 4. Probability distribution of rain spell duration for rain exceeding various percentile thresholds. Results are shown for (a) radar and model differences for (b),(e) $12 \mathrm{~km}$ - radar, (c),(f) $1.5 \mathrm{~km}$ - radar, and (d) $1.5 \mathrm{~km}-12 \mathrm{~km}$ (where $x \mathrm{~km}$ refers to the RCM with a resolution of $x \mathrm{~km}$ ). Results correspond to 2003-10 for the radar, and (b),(c) 1990-97 or (d)-(f) 2000-07 for the models. Percentile thresholds are defined in Fig. 3; probabilities are calculated across all southern U.K. grid boxes and all eight years in the respective datasets. Differences that are not significant at the $1 \%$ level are masked in gray, zero probabilities are masked in white. 
(a) Radar

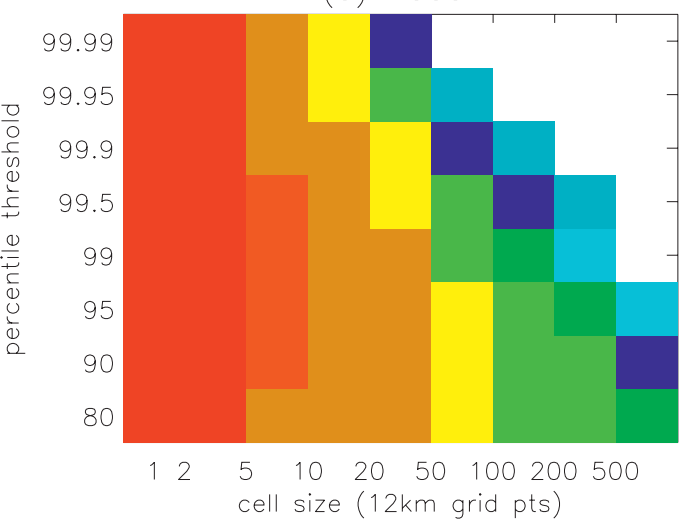

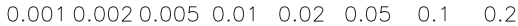

(b) $12 \mathrm{~km}$ - radar, $1990-1997$
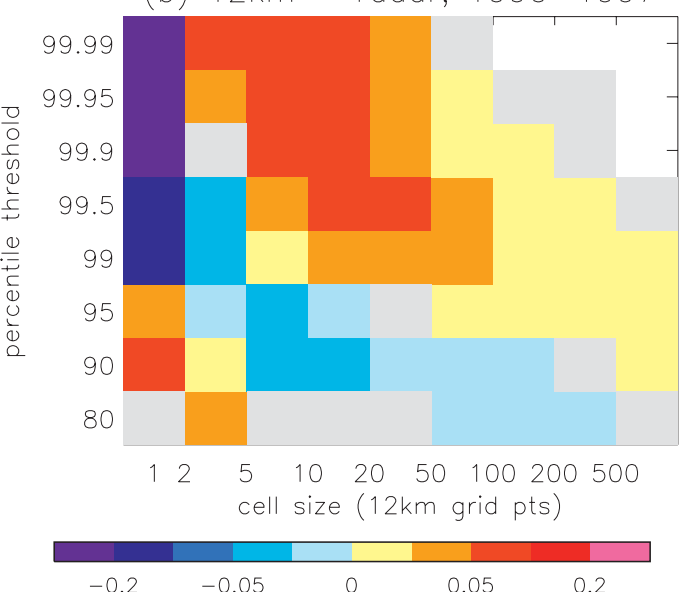

(c) $1.5 \mathrm{~km}$ - radar, $1990-1997$

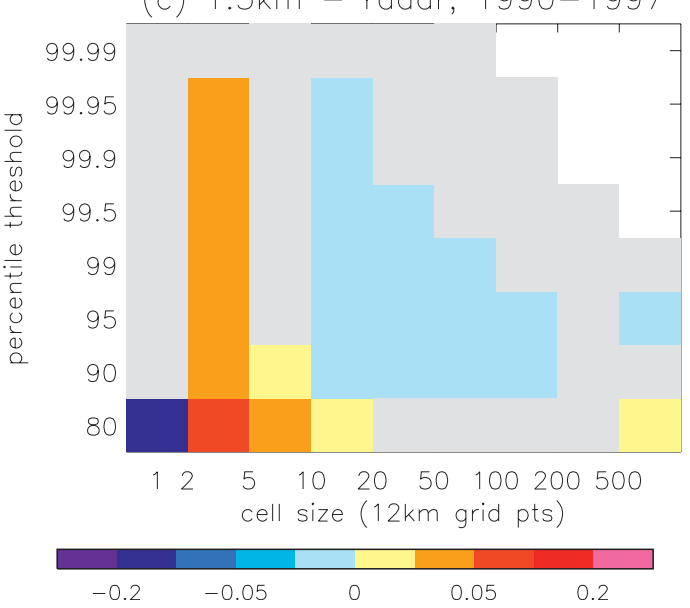

(d) $1.5 \mathrm{~km}-12 \mathrm{~km}, 2000-2007$

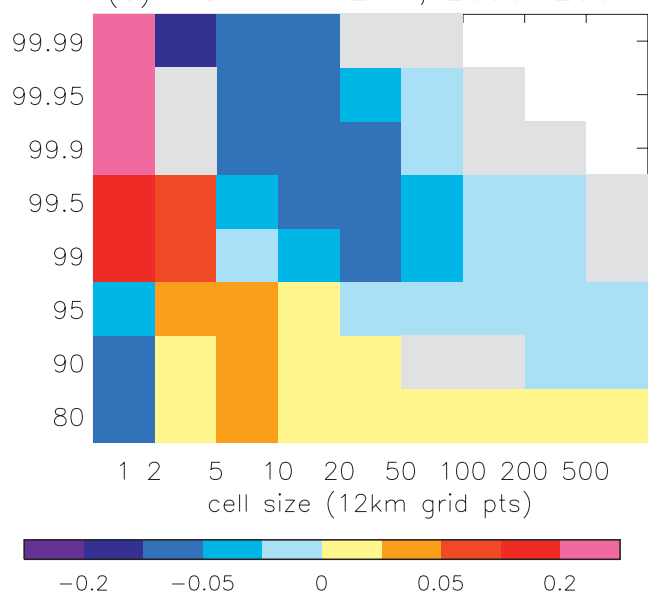

(e) $12 \mathrm{~km}$ - radar, 2000-2007

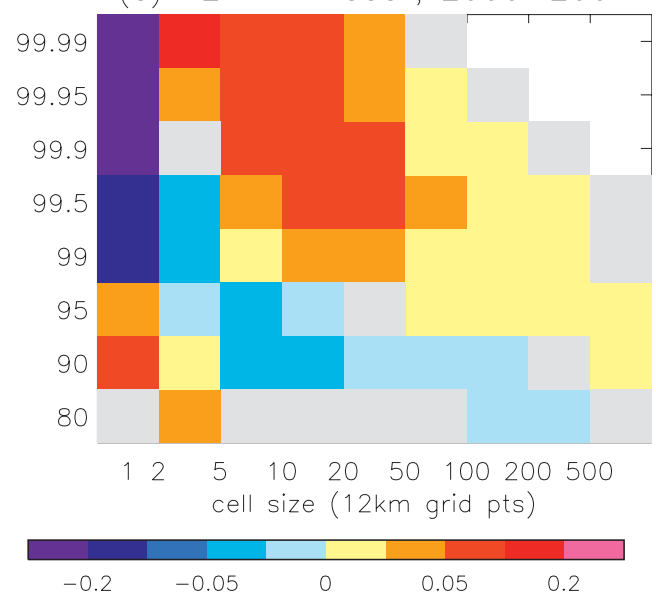

(f) $1.5 \mathrm{~km}$ - radar, $2000-2007$

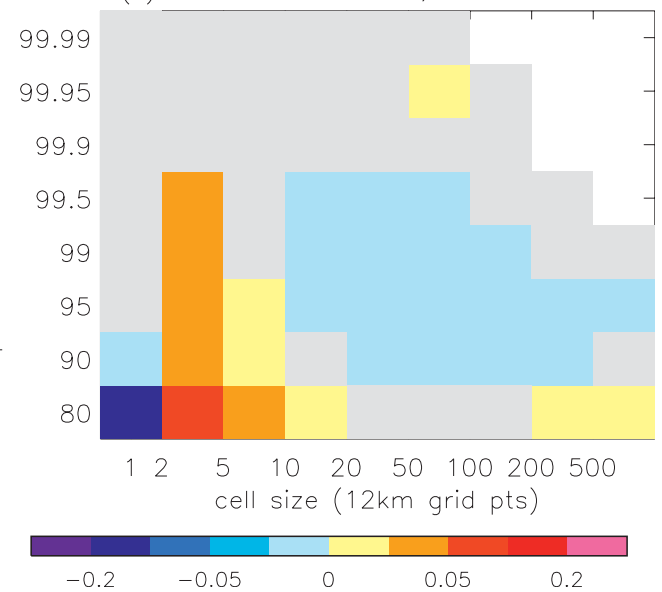

FIG. 5. Probability distribution of rain cell size for rain exceeding various percentile thresholds, definitions as in Fig. 4.

12-km grid boxes. This bias is largely reversed when light to moderate rain events are also considered (percentile thresholds $\leq 95$ ), for which the $12-\mathrm{km}$ RCM shows too many small rain cells.
In the $1.5-\mathrm{km} \mathrm{RCM}$, heavy rain is more localized than in the $12-\mathrm{km} \mathrm{RCM}$, leading to considerably better agreement with the radar. The $1.5-\mathrm{km}$ RCM shows a tendency for too many small cells (from two to four $12-\mathrm{km}$ 
grid boxes), but otherwise few significant differences in the number of both very small (single grid box) and large heavy rain cells compared to the radar. It is notable that these differences are robust to the choice of model years, with similar results for 1990-97 and 2000-07. These results indicate that there may be a slight tendency for rain cells to lock to a particular size in the $1.5-\mathrm{km} \mathrm{RCM-}$ something that might be happening in the UKV forecast model and may be associated with the representation of subgrid processes in convective clouds (see section 4). Again we find that these results are consistent across the different regions and seasons.

\section{d. Rainfall duration versus peak intensity}

The above analysis focused on the spatial and temporal characteristics of heavy rain, considering only those parts of rainfall events exceeding a given threshold. However, the heaviest rain, which tends to be shortlived and localized, may be embedded within a larger or more prolonged, lower intensity event. We examine this here by considering all rainfall exceeding a $0.1 \mathrm{~mm} \mathrm{~h}^{-1}$ threshold and investigating how the duration of the entire rainfall event is related to its peak intensity.

In the radar, low peak intensity events tend to be short-lived, while moderate peak intensities are generally associated with longer-lived events (Fig. 6). High peak intensities $\left(>10 \mathrm{~mm} \mathrm{~h}^{-1}\right)$ are relatively infrequent, but when they do occur they can be embedded within a wide range of events lasting from just one hour up to about one day. Significant differences in this distribution are seen in the $12-\mathrm{km}$ RCM compared to the radar. In particular, the 12-km RCM has too few shortduration mid-to-high peak intensity events and too many long-duration and lower-intensity events. By comparison, the $1.5-\mathrm{km}$ RCM has significantly more short-duration mid-to-high peak rainfall than the 12-km $\mathrm{RCM}$ and fewer long-duration lower-intensity events (Fig. 6d). Indeed, the comparison between the 12-km $\mathrm{RCM}$ and radar and the $1.5-\mathrm{km}$ - and 12-km RCMs looks like the inverse of each other (cf. Fig. 6e to $6 \mathrm{~d}$ ). As a result, the $1.5-\mathrm{km}$ RCM gives much better agreement with the radar, although it still shows a slight tendency for too little short-duration rain. Again these results are robust to the choice of model years.

We note that in this analysis where we are comparing absolute precipitation amounts, known radar biases may contribute to the model - radar differences. In particular, the radar is known to miss light precipitation, which may lead to an underestimation of rainfall duration and it also underestimates the intensity of heavy rain. The former may exacerbate the tendency for models to show too little short-duration rain, but is not expected to be the sole explanation for this difference. The latter bias may contribute to some of the apparent overestimation in the number of high-peak intensity events in the $1.5-\mathrm{km}$ RCM.

\section{e. Character of convective versus large-scale rain}

To examine whether the $1.5 \mathrm{~km}-12 \mathrm{~km}$ RCM differences in the characteristics of precipitation are related to specific rainfall regimes, we examine differences on days of high and low convection fraction. The diagnosis of convective versus large-scale precipitation in the $12-\mathrm{km}$ RCM is used to calculate the convective fraction $(\mathrm{CF})$ on each day at each grid box. We then examine the duration of peak intensity characteristics, only including those days and grid boxes where $\mathrm{CF}$ is within a given range. By calculating $\mathrm{CF}$ on a daily basis we are neglecting regime changes on subdaily time scales. Also, we assume that the CF in the $12-\mathrm{km}$ RCM can be used to categorize days in the $1.5-\mathrm{km} \mathrm{RCM}$. In the $1.5-\mathrm{km}$ RCM, the convection scheme is switched off, so there is no model diagnosis of convection occurrence. However, given the small size of the $1.5-\mathrm{km} \mathrm{RCM} \mathrm{do-}$ main, we expect good agreement in the daily meteorological patterns between the $1.5-\mathrm{km} \mathrm{RCM}$ and the driving 12-km RCM, and hence reasonable day-to-day correspondence in the precipitation regime. The same, however, is not true between the models and observations. The 12-km RCM domain is sufficiently large that information on the observed state fed in at the lateral boundaries will not strongly constrain the evolution and position of mesoscale weather systems and fronts in the interior and therefore over the United Kingdom. Thus, the 12-km RCM's diagnosis of CF (even for corresponding dates) cannot be applied to the radar data.

In the $1.5-\mathrm{km}$ RCM, there is more short-lived high peak intensity rainfall on days of high convective fraction $(\mathrm{CF}>0.7)$ compared to days of lower CF (Fig. 7). The difference is greatest comparing high $\mathrm{CF}$ days with very low $\mathrm{CF}$ days $(\mathrm{CF}<0.1)$, but a consistent pattern is seen for other CF categories. The 12-km RCM, however, shows a very different result. In this case, convective precipitation is not associated with more short-lived high-intensity events but rather more moderate-intensity events of up to several hours duration. High peak intensities in the $12-\mathrm{km} \mathrm{RCM}$ are more likely to be associated with large-scale than convective rain. These results correspond to the years 1990-97 in the models; however, we note that very similar results are obtained if the analysis is, instead, performed for the years 2000-07 (not shown).

The difference in the character of convective versus large-scale precipitation seen in the $1.5-\mathrm{km}$ RCM is much more realistic. In particular, studies of observed 
(a) Radar

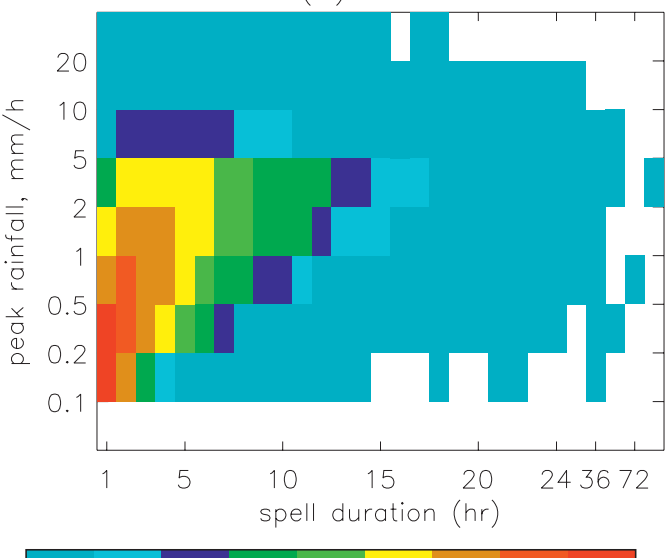

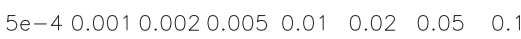

(b) $12 \mathrm{~km}$ - radar, $1990-1997$
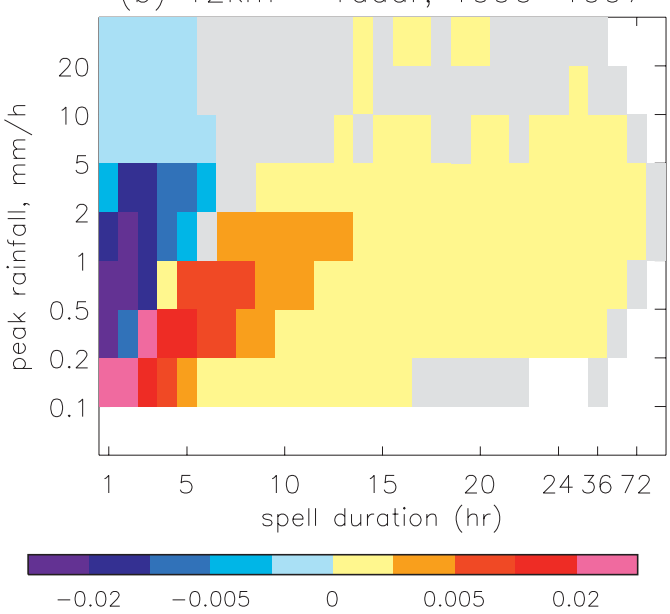

(c) $1.5 \mathrm{~km}$ - radar, $1990-1997$

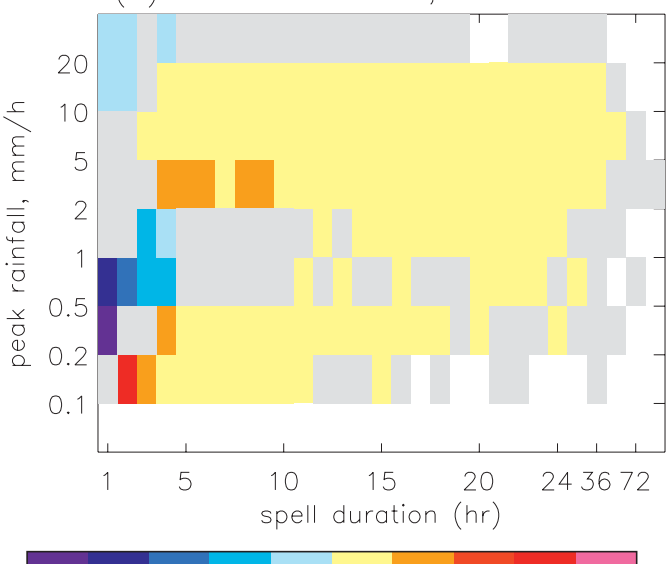

$-0.02$

$-0.005$

0.005

0.02

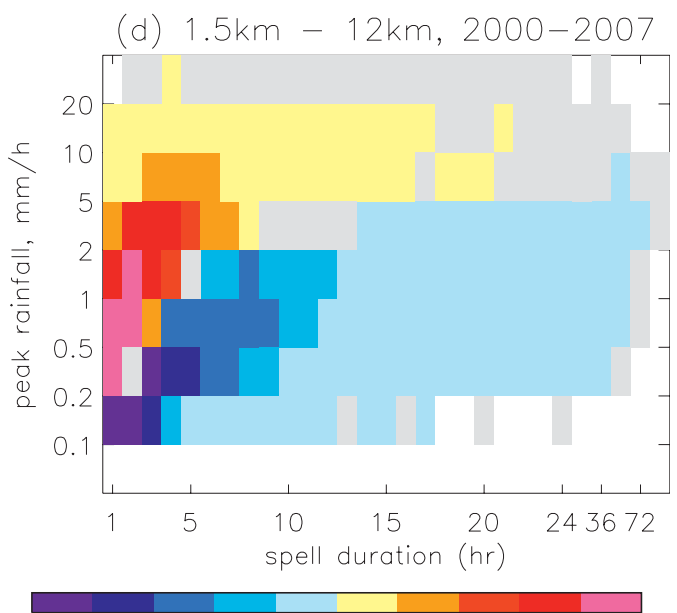

$-0.02$

0.005

0.02

(e) $12 \mathrm{~km}$ - radar, 2000-2007

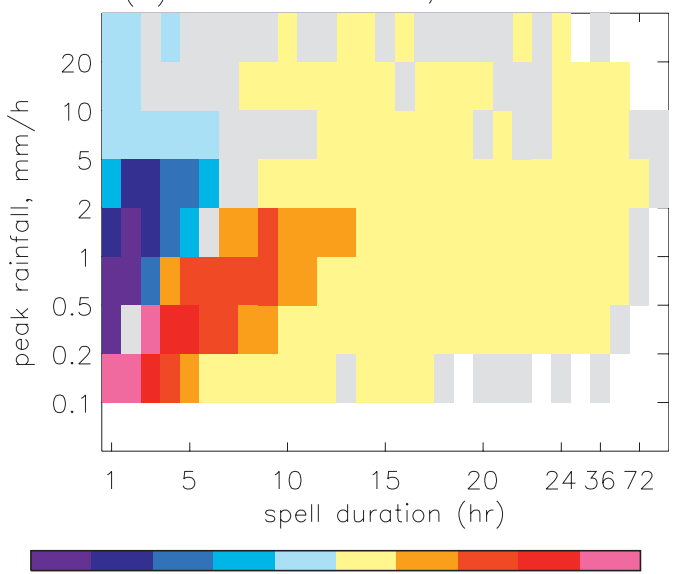

$-0.02$

0.005

0.02

(f) $1.5 \mathrm{~km}$ - radar, 2000-2007

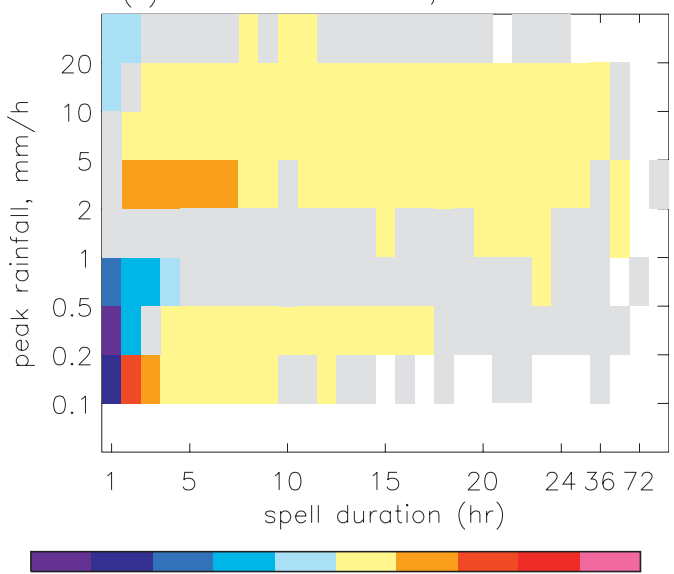

$\begin{array}{lllll}-0.02 & -0.005 & 0 & 0.005 & 0.02\end{array}$

FIG. 6. Joint probability distribution of rain spell duration vs peak amount for rain exceeding $0.1 \mathrm{~mm} \mathrm{~h}^{-1}$. Results are shown for (a) radar and model differences, (b),(e) $12 \mathrm{~km}$ - radar, (c),(f) $1.5 \mathrm{~km}$ - radar, and (d) $1.5 \mathrm{~km}-12 \mathrm{~km}$. Results correspond to 2003-10 for the radar, and (b),(c) 1990-97 or (d)-(f) 2000-07 for the models. The probability distribution is calculated across all southern U.K. grid boxes and all years in the respective datasets. Differences that are not significant at the $1 \%$ level are masked in gray, zero probabilities are masked in white. 
(a)

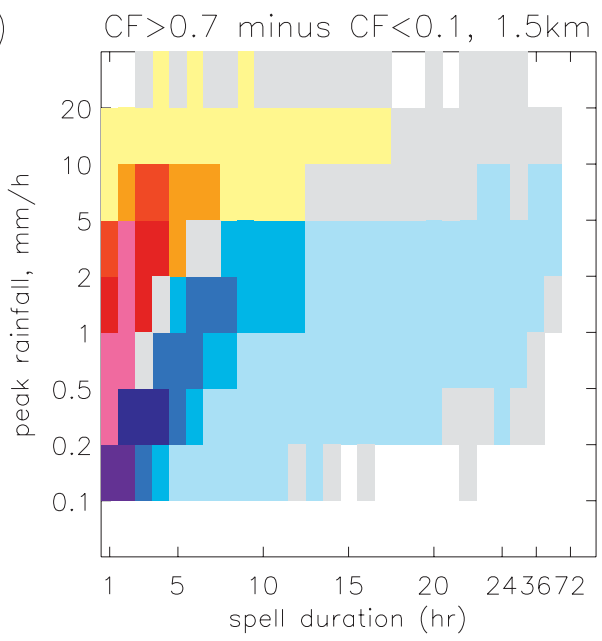

(b)

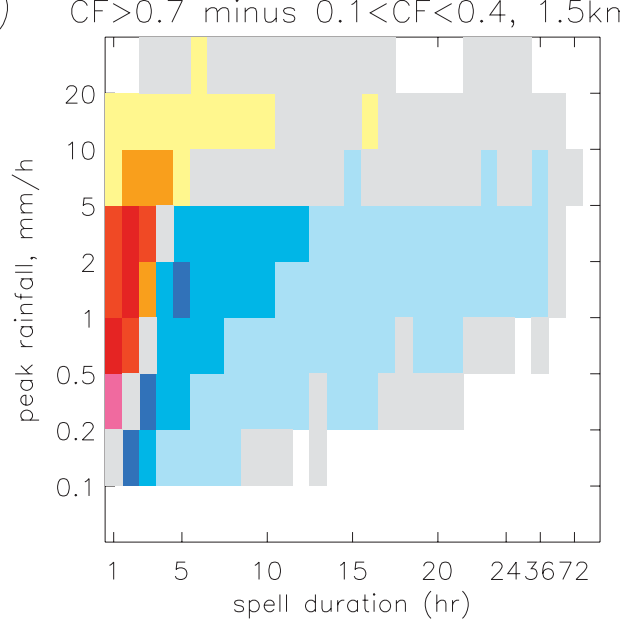

(c)
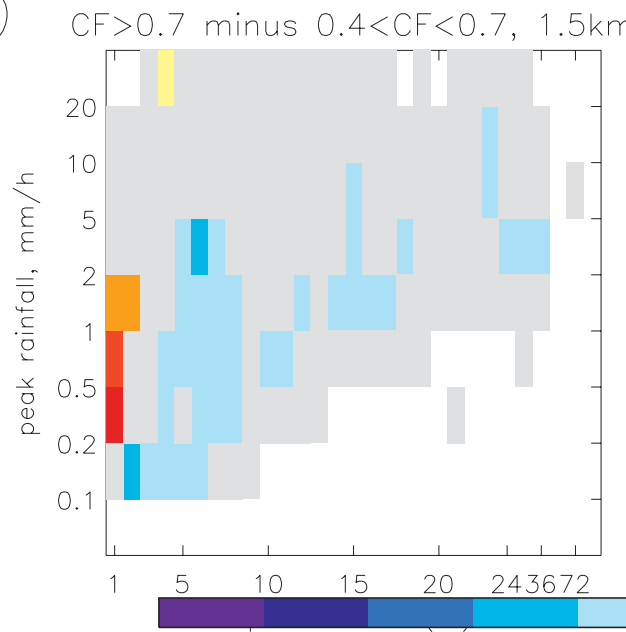

$-0.02$

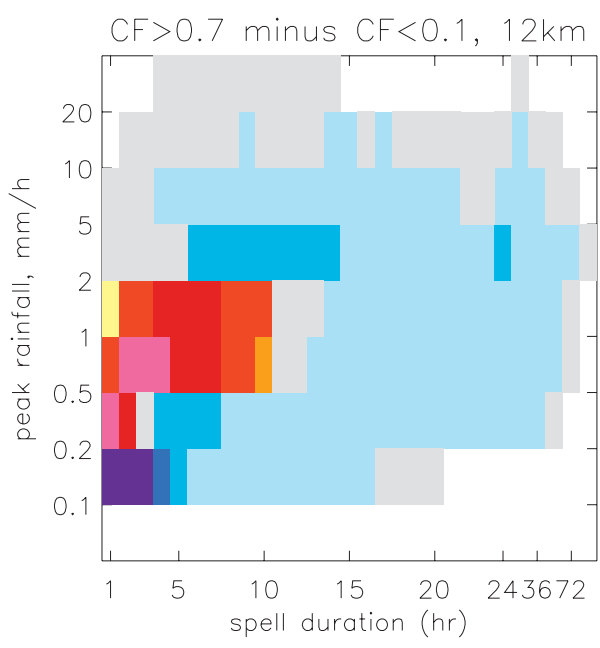

CF $>0.7$ minus $0.1<\mathrm{CF}<0.4,12 \mathrm{~km}$

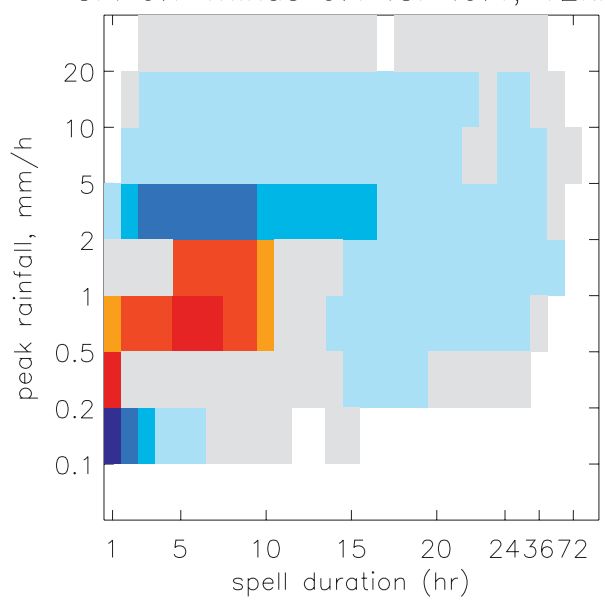

CF $>0.7$ minus $0.4<C F<0.7,12 \mathrm{~km}$

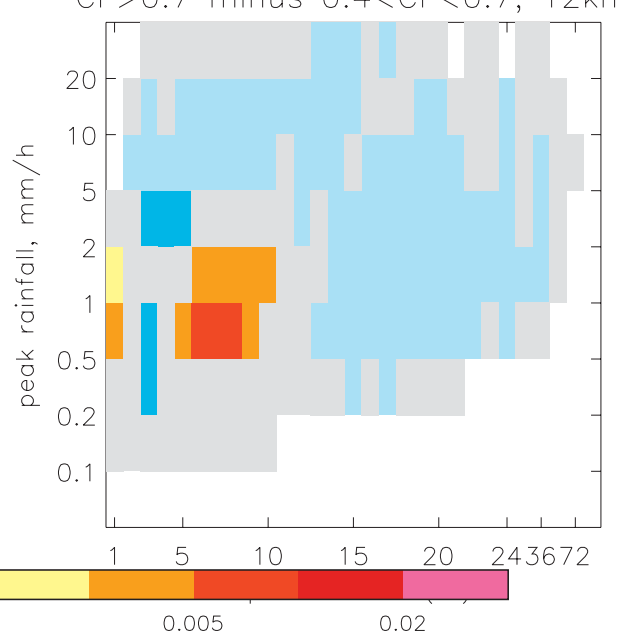

FIG. 7. Differences in the joint probability distribution of rain spell duration vs peak amount for different rainfall regimes. Differences are shown between days of high convective fraction ( $\mathrm{CF}>0.7)$ and days of (a) very low $(\mathrm{CF}<$ $0.1)$, (b) low $(0.1<\mathrm{CF}<0.4)$, and (c) moderate $(0.4<\mathrm{CF}<0.7)$ convective fraction for the (left) $1.5-\mathrm{km}$ and (right) 12-km RCMs for 1990-97. Definitions are as in Fig. 6. 
rainfall events across the United Kingdom show that convective rain is typically characterized by short-lived intense events (Hand et al. 2004). It is notable that differences in the $1.5-\mathrm{km} \mathrm{RCM}$ for high versus low CF regimes in Fig. 7 mirror the 1.5-km-RCM differences from the 12-km RCM in Fig. 6. This strongly suggests that the model differences in the duration-intensity characteristics of precipitation are primarily due to an improved representation of convection in the $1.5-\mathrm{km} \mathrm{RCM}$.

We note that early work using spatial gradients in the rainfall field has been successful at diagnosing convective versus stratiform rain in the radar. This method has also been applied to the $1.5-\mathrm{km} \mathrm{RCM}$ as an alternative to using the $12-\mathrm{km}$ RCM model diagnosis. These early results (not shown) indicate that the $1.5-\mathrm{km} \mathrm{RCM}$ gives a much better representation of the intensity-duration characteristics of convective rain, with convection in the 12-km RCM being too persistent and low intensity. Thus this supports the results presented here using the model's convective diagnosis.

\section{f. Diurnal cycle of convection}

The diurnal cycle of rainfall across the southern United Kingdom, in the $1.5-\mathrm{km}$ and $12-\mathrm{km}$ RCMs, is shown in Fig. 8. In particular, we show the diurnal cycle of precipitation for all days, allowing a comparison between the models and radar, and also on days of high convective fraction $(\mathrm{CF}>0.7)$ for the models only. Again we use the 12-km RCM's diagnosis of convective versus large-scale rain to calculate $\mathrm{CF}$.

We expect the diurnal cycle of precipitation for all days to be dominated by the timing of convection. This is because the occurrence of frontal precipitation does not depend on the time of day. Thus, the inclusion of frontal precipitation will weaken the diurnal cycle but is not expected to shift the timing of the peak. Even when considering all days, the $12-\mathrm{km}$ RCM shows a pronounced midday peak. The $1.5-\mathrm{km}$ RCM, by contrast, shows a much weaker diurnal cycle with a midafternoon peak, which appears to be in much better agreement with the radar. We note that this behavior is consistent for both model periods considered.

On days with a high convective fraction $(\mathrm{CF}>0.7)$, the $1.5-\mathrm{km}$ RCM again shows a weaker diurnal cycle compared to the 12-km RCM, with the peak shifted later into the afternoon. In particular, in the $1.5-\mathrm{km}$ RCM there is a delay in the onset of convection and a slower decay of convection in the afternoon. This represents a considerable improvement, with the tendency for coarser resolution NWP and climate models to develop convection too early in the day being a well-known problem (Lean et al. 2008; Stratton and Stirling 2012).

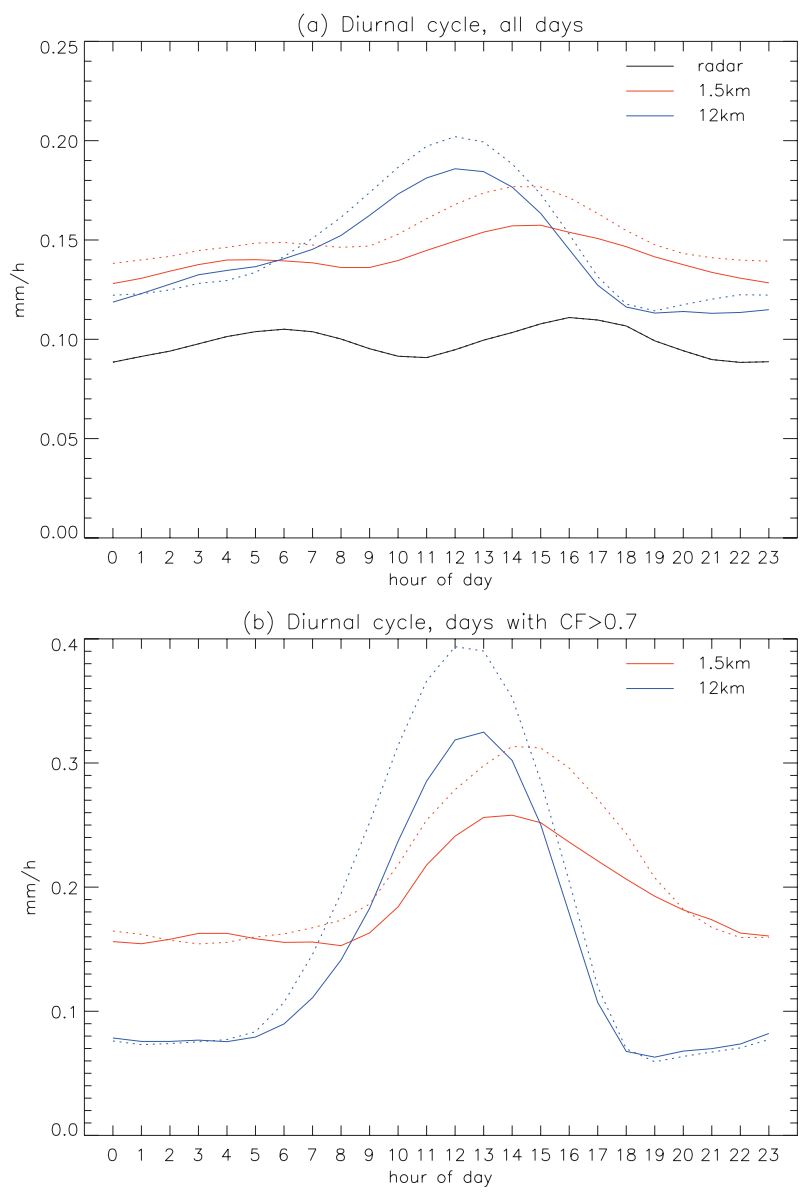

FIG. 8. Diurnal cycle of rainfall for (a) all days and (b) days of high convective fraction $(\mathrm{CF}>0.7)$ in the radar [in (a) only] and the $1.5-\mathrm{km}$ and $12-\mathrm{km}$ RCMs. Results correspond to 2003-10 in the radar, and 1990-97 (solid lines) and 2000-07 (dotted lines) in the models. The mean rainfall is plotted at each hour of the day, across all southern U.K. grid boxes and all eight years in the respective datasets.

\section{Discussion and conclusions}

In this study we have examined the realism of rainfall in a $1.5-\mathrm{km}$ regional climate model $(1.5-\mathrm{km} \mathrm{RCM})$ compared to a $12-\mathrm{km}$ regional climate model $(12-\mathrm{km}$ $\mathrm{RCM})$. A complete and stringent test of model performance should encompass the full spatial and temporal structure of rain, across a wide range of space and time scales and as a function of the meteorological situation. In this paper we have examined a number of different metrics, which look at different aspects of the spatial and temporal structure of hourly rainfall. As such, this represents a first attempt at assessing realism, but many other metrics would be needed to fully capture all aspects.

In general, the results here suggest that rainfall is much more realistic in the $1.5-\mathrm{km}$ RCM than in the $12-\mathrm{km}$ RCM. A key focus has been on heavy rain, and we find that, although the $1.5-\mathrm{km} \mathrm{RCM}$ appears to have 
a tendency for heavy rain to be too intense, it gives a much better representation of its spatial and temporal structure. In the $12-\mathrm{km} \mathrm{RCM}$, heavy rain events are not heavy enough, and tend to be too persistent and widespread. There are also not enough short-duration high peak intensity events overall, which appears to be linked to deficiencies in the representation of convective rain. These biases are significantly reduced in the $1.5-\mathrm{km} \mathrm{RCM}$.

In addition to heavy rain, we have also considered characteristics of the wider hourly rainfall distribution where there are known deficiencies in current climate models. In particular, the tendency for too much persistent light rain is a common problem in climate models. This error is considerably reduced in the $1.5-\mathrm{km}$ RCM, which shows many more dry spells. Another longstanding problem relates to the timing of convection, and we find that the $1.5-\mathrm{km}$ RCM gives a much better representation of the diurnal cycle, with convection peaking later in the day. As shown in Hohenegger et al. (2009), an improvement in the timing of convection can have significant consequences for soil moistureprecipitation feedback over the Alpine region and hence the potential to impact climate processes on longer time scales. It is unclear whether similar processes may also operate over the United Kingdom, and this will be examined in future research.

The analysis of rainfall duration here has been done in an Eulerian frame; namely, the durations of events are examined at a given point in space rather than in the frame of the moving cell. This approach is clearly of relevance to flooding, but has the disadvantage that a short spell of rain may result equally well from a short-lived stationary shower or a long-lived fast-moving shower. As a result, model errors in rainfall duration and cell size, reported here, are not independent. In particular, the tendency for rainfall to be too widespread in the $12-\mathrm{km}$ RCM will also lead to rainfall tending to be too persistent at a given location (except when the event in question is actually stationary). In terms of understanding the underlying source of model deficiencies, it would be good to disentangle errors in the spatial extent and lifetime of rainfall. This would require the analysis to be done in a Lagrangian frame, employing a cell-tracking algorithm, which is beyond the scope of the current paper but will be the topic of future research.

A key source of the improvement in the $1.5-\mathrm{km} \mathrm{RCM}$ is expected to be that it no longer relies on a convective parameterization scheme, with most convection over the United Kingdom satisfactorily represented on the model grid. The NWP case studies have shown that the $1.5-\mathrm{km}$ model is able to represent many of the important processes controlling the development and persistence of convection. These include the local dynamical and topographical forcing leading to convective triggering and inhibition (e.g., convergence lines), storm organization and secondary cell development, the development of convective outflows, and environmental mixing (Roberts 2007). Thus, the fact that the model is able to realistically represent the spatial and temporal structure of rainfall, found here, is likely to be a reflection of an improved representation of these underlying processes. We note, however, that convection is "permitted" but still not properly resolved at $1.5 \mathrm{~km}$, and the grid spacing is still too coarse to resolve updrafts that are narrower than several kilometers. This means that some showers will have updrafts on the wrong scale with inherently insufficient turbulent mixing and explains the tendency for vertical velocities, and hence the intensity of convective showers, to be too strong in some situations in kilometer-scale models (Lean et al. 2008). The inclusion of the Smagorinsky-Lilly turbulence diffusion has alleviated this problem by representing subgrid mixing, particularly between updrafts and environmental air. However, it does not properly solve the issue of how to represent the underresolved updrafts, and this is an active area of research in storm-permitting forecast models. The underresolving of showers may also explain the tendency for rain cells to lock to a particular size (of two to four 12-km grid lengths) in the 1.5-km RCM since the high vertical velocities may make cells too intense and upright and inhibit growth. Nevertheless, we must reiterate that despite the issues raised above, the $1.5-\mathrm{km}$ RCM gives a considerably more realistic representation of convection than at $12 \mathrm{~km}$.

In the $12-\mathrm{km} \mathrm{RCM}$, convection is represented by a convective parameterization scheme. This aims to describe the average properties of convection over a grid box. It is not designed to represent individual showers. Thus we would not expect individual rainfall events to be well represented, but we would hope that the average spatial and temporal characteristics of convection would be captured. The results here suggest that the higher rainfall totals from convection in the RCM are too low and that the precipitation is too widespread and persistent. The convective precipitation also peaks too early in the day because the convection scheme responds to the local instability and is unable to organize convection (Roberts and Lean 2008) into the evening, with no memory in the scheme from one time step to the next. We note that not all of the deficiencies in the $12-\mathrm{km} \mathrm{RCM}$ found here are attributable directly to the convection scheme. In particular, much of the persistent light rain in the $12-\mathrm{km}$ RCM comes from the large-scale scheme. The $1.5-\mathrm{km}$ model is better in this regard and benefits from the use of prognostic rain, whereby rain droplets are transported by winds and can evaporate while falling 
(section 2a). Recent inclusion of this scheme has led to improvements in global and regional climate models.

Further detailed investigation of the underlying processes is needed to get a better grasp of model deficiencies at both resolutions. In particular, the $1.5-\mathrm{km}$ climate runs provide an invaluable dataset for examining the underlying processes, which will be exploited in future research.

The realism of rainfall in a climate model is a key indicator of its skill in representing the underlying physical processes and, hence, for projecting future changes in rainfall. In particular, the spatial and temporal structure of rainfall is arguably more important than the absolute rainfall amount, which is typically used to assess model skill. Therefore the fact that rainfall in the $1.5-\mathrm{km} \mathrm{RCM}$ is more realistic gives us more confidence in its future projections. Based on these results, we are now embarking on climate change experiments with the $1.5-\mathrm{km}$ RCM. Of particular interest is whether the $1.5 \mathrm{~km}$ RCM shows a change in the spatial and temporal characteristics of heavy rainfall in a warmer climate, which is unlikely to be captured by coarser resolution models. Accurately predicting such changes is essential if we are to estimate changes in flood risk. Also, if there are significant changes in these characteristics, this will have important implications for our confidence in current climate model projections of rainfall change. In particular, it may indicate that the representation of local storm dynamics is important for predicting future changes in precipitation extremes.

We must proceed with caution though and be aware that our confidence in future projections is also highly dependent on the ability of the coarser-resolution driving model to represent the synoptic and mesoscale variability, which is important for constraining the local rainfall, and any changes in this (e.g., a shift in the storm track) that could have a significant impact on precipitation over the United Kingdom. There is also the issue of relating any signal in the heavier precipitation events to more extreme precipitation that produces floods. The hope is that the analysis of changes at convection-permitting scales will allow us to identify the relative importance of local processes in controlling future changes in precipitation, conditional on the larger-scale environment. An assumption implicit in the one-way nesting of models used here is that the large-scale patterns do not diverge strongly between the limited-area model and the coarser-resolution driving model (Jones et al. 1997), and thus any feedback of local processes on the large scale cannot be investigated using this approach.

Acknowledgments. First, thanks to colleagues across the Met Office for their help setting up the $1.5-\mathrm{km}$-model experiments, especially David Hassell, Chang Wang, Jorge Bornemann, Steve Mullerworth, and Clive Jones. Particular thanks to Wilfran Moufoumia-Okia for running the 12-km-RCM experiments and help running the 1.5-km experiments. Also we thank David Sexton for advice on statistical approaches, and Humphrey Lean, Simon Brown, and Richard Jones for useful discussions. We gratefully acknowledge funding from the Joint Department of Energy and Climate Change (DECC) and Department for Environment Food and Rural Affairs (Defra) Met Office Hadley Centre Climate Programme (GA01101). This work also forms part of a joint Met Office and Natural Environment Research Council (UKMO-NERC)-funded project on Convective Extremes (CONVEX).

\section{REFERENCES}

Boberg, F., P. Berg, P. Thejll, W. J. Gutowski, and J. H. Christensen, 2009: Improved confidence in climate change projections of precipitation evaluated using daily statistics from the PRUDENCE ensemble. Climate Dyn., 32, 1097-1106.

,,,,---- and,- 2010 : Improved confidence in climate change projections of precipitation further evaluated using daily statistics from ENSEMBLES models. Climate Dyn., 35, 1509-1520.

Brockhaus, P., D. Lüthi, and C. Schär, 2008: Aspects of the diurnal cycle in a regional climate model. Meteor. Z., 17, 433443.

Brown, A. R., S. H. Derbyshire, and P. J. Mason, 1994: Large-eddy simulation of stable atmospheric boundary layers with a revised stochastic subgrid model. Quart. J. Roy. Meteor. Soc., 120, 1485-1512.

Christensen, J. H., and O. B. Christensen, 2007: A summary of the PRUDENCE model projections of changes in European climate by the end of this century. Climatic Change, $\mathbf{8 1}$ (Suppl.), 7-30.

— Change 2007: The Physical Science Basis, S. Solomon et al., Eds., Cambridge University Press, 847-940.

Cullen, M. J. P., 1993: The unified forecast/climate model. Meteor. Mag., 122, 81-94.

Dai, A., 2006: Precipitation characteristics in eighteen coupled climate models. J. Climate, 19, 4605-4630.

Davies, T., M. J. P. Cullen, A. J. Malcolm, M. H. Mawson, A. Stainforth, A. A. White, and N. Wood, 2005: A new dynamical core for the Met Office's global and regional modelling of the atmosphere. Quart. J. Roy. Meteor. Soc., 131, 1759-1782, doi:10.1256/qj.04.101.

Dee, D. P., and Coauthors, 2011: The ERA-Interim reanalysis: Configuration and performance of the data assimilation system. Quart. J. Roy. Meteor. Soc., 137, 553-597, doi:10.1002/ qj.828.

Essery, R., M. Best, and P. Cox, 2001: MOSES 2.2 technical documentation. Hadley Centre Tech. Note 30, $31 \mathrm{pp}$.

Fowler, H. J., and M. Ekström, 2009: Multi-model ensemble estimates of climate change impacts on UK seasonal precipitation extremes. Int. J. Climatol., 29, 385-416.

- — - S. Blenkinsop, and A. P. Smith, 2007: Estimating change in extreme European precipitation using a multimodel 
ensemble. J. Geophys. Res., 112, D18104, doi:10.1029/ 2007JD008619.

Frei, C., R. Schöll, S. Fukutome, J. Schmidli, and P. L. Vidale, 2006: Future change of precipitation extremes in Europe: Intercomparison of scenarios from regional climate models. J. Geophys. Res., 111, D06105, doi:10.1029/2005JD005965.

Golding, B. W., 1998: Nimrod: A system for generating automated very short range forecasts. Meteor. Appl., 5, 1-16.

Gregory, D., and P. R. Rowntree, 1990: A mass-flux convection scheme with representation of cloud ensemble characteristics and stability-dependent closure. Mon. Wea. Rev., 118, 14831506.

Hand, W. H., N. I. Fox, and C. G. Collier, 2004: A study of twentiethcentury extreme rainfall events in the United Kingdom with implications for forecasting. Meteor. Appl., 11, 15-31, doi: 10.1017/S1350482703001117.

Harrison, D. L., S. J. Driscoll, and M. Kitchen, 2000: Improving precipitation estimates from weather radar using quality control and correction techniques. Meteor. Appl., 7, 135-144, doi:10.1017/S1350482700001468.

Hohenegger, C., P. Brockhaus, and C. Schär, 2008: Towards climate simulations at cloud-resolving scales. Meteor. Z., 17, 383-394, doi:10.1127/0941-2948/2008/0303.

, C. S. Bretherton, and C. Schär, 2009: The soil moistureprecipitation feedback in simulations with explicit and parameterized convection. J. Climate, 22, 5003-5020.

Jones, R. G., J. M. Murphy, M. Noguer, and A. B. Keen, 1997: Simulation of climate change over Europe using a nested regional-climate model. II: Comparison of driving and regional model responses to a doubling of carbon dioxide. Quart. J. Roy. Meteor. Soc., 123, 265-292.

Kendon, E. J., D. P. Rowell, and R. G. Jones, 2010: Mechanisms and reliability of future projected changes in daily precipitation. Climate Dyn., 35, 489-509, doi:10.1007/s00382-0090639-z.

Kjellström, E., F. Boberg, M. Castro, J. H. Christensen, G. Nikulin, and E. Sánchez, 2010: Daily and monthly temperature and precipitation statistics as performance indicators for regional climate models. Climate Res., 44, 135-150, doi:10.3354/cr00932.

Knote, C., G. Heinemann, and B. Rockel, 2010: Changes in weather extremes: Assessment of return values using high resolution climate simulations at convection-resolving scale. Meteor. Z., 19, 11-23, doi:10.1127/0941-2948/2010/0424.

Lean, H. W., P. A. Clark, M. Dixon, N. M. Roberts, A. Fitch, R. Forbes, and C. Halliwell, 2008: Characteristics of highresolution versions of the Met Office Unified Model for forecasting convection over the United Kingdom. Mon. Wea. Rev., 136, 3408-3424.

Lenderink, G., and E. van Meijgaard, 2008: Increase in hourly precipitation extremes beyond expectations from temperature changes. Nat. Geosci., 1, 511-514.

Lilly, D. K., 1962: On the numerical simulation of buoyant convection. Tellus, 14A, 148-171.

Lock, A. P., A. R. Brown, M. R. Bush, G. M. Martin, and R. N. B. Smith, 2000: A new boundary layer mixing scheme. Part I: Scheme description and single-column model tests. Mon. Wea. Rev., 128, 3187-3199.
Maraun, D., and Coauthors, 2010: Precipitation downscaling under climate change: Recent developments to bridge the gap between dynamical models and the end user. Rev. Geophys., 48, RG3003, doi:10.1029/2009RG000314.

May, W., 2007: The simulation of the variability and extremes of daily precipitation over Europe by the HIRHAM regional climate model. Global Planet. Change, 57, 59-82, doi:10.1016/ j.gloplacha.2006.11.026.

Rauscher, S. A., E. Coppola, C. Piani, and F. Giorgi, 2010: Resolution effects on regional climate model simulations of seasonal precipitation over Europe. Climate Dyn., 35, 685-711.

Reynolds, R. W., T. M. Smith, C. Liu, D. B. Chelton, K. S. Casey, and M. G. Schlax, 2007: Daily high-resolution blended analyses for sea surface temperature. J. Climate, 20, 5473-5496.

Roberts, N. M., 2007: Meteorological components in forecasts of extreme convective rainfall using 12-km and 1-km NWP models: A tale of two storms. Forecasting Research Tech. Rep. 520, 58 pp.

_ and H. W. Lean, 2008: Scale-selective verification of rainfall accumulations from high-resolution forecasts of convective events. Mon. Wea. Rev., 136, 78-97.

— S. Cole, R. M. Forbes, R. Moore, and D. Boswell, 2009: Use of high-resolution NWP rainfall and river flow forecasts for advance warning of the Carlisle flood, north-west England. Meteor. Appl., 16, 23-34, doi:10.1002/met.94.

Schwartz, C. S., and Coauthors, 2009: Next-day convection-allowing WRF model guidance: A second look at $2-\mathrm{km}$ versus $4-\mathrm{km}$ grid spacing. Mon. Wea. Rev., 137, 3351-3372.

Smagorinsky, J., 1963: General circulation experiments with the primitive equations. Part I: The basic experiments. Mon. Wea. Rev., 91, 99-164.

Solomon, S., D. Qin, M. Manning, M. Marquis, K. Averyt, M. M. B. Tignor, H. L. Miller Jr., and Z. Chen, Eds., 2007: Climate Change 2007: The Physical Science Basis. Cambridge University Press, $996 \mathrm{pp}$.

Stratton, R. A., and A. J. Stirling, 2012: Improving the diurnal cycle of convection in GCMs. Quart. J. Roy. Meteor. Soc., 138, 11211134, doi:10.1002/qj.991.

Swann, H., 2001: Evaluation of the mass-flux approach to parametrizing deep convection. Quart. J. Roy. Meteor. Soc., 127, 1239-1260.

Wakazuki, Y., M. Nakamura, S. Kanada, and C. Muroi, 2008: Climatological reproducibility evaluation and future climate projection of extreme precipitation events in the baiu season using a high-resolution non-hydrostatic RCM in comparison with an AGCM. J. Meteor. Soc. Japan, 86, 951-967.

Walters, D. N., and Coauthors, 2011: The Met Office Unified Model Global Atmosphere 3.0/3.1 and JULES Global Land 3.0/3.1 configurations. Geosci. Model Dev. Discuss., 4, 12131271, doi:10.5194/gmdd-4-1213-2011.

Weusthoff, T., F. Ament, M. Arpagaus, and M. W. Rotach, 2010: Assessing the benefits of convection-permitting models by neighborhood verification: Examples from MAP D-PHASE. Mon. Wea. Rev., 138, 3418-3433.

Wilson, D. R., and S. P. Ballard, 1999: A microphysically based precipitation scheme for the UK Meteorological Office Unified Model. Quart. J. Roy. Meteor. Soc., 125, 1607-1636. 